\title{
A Content Analysis of the Journal of Legal Aspects of Sport: 1992-2016
}

\section{John J. Miller, Andy Gillentine, Andrew Olinger, and Sara Vogt*}

Academic journals serve as forums for the introduction and presentation of new research as well as for scrutiny and critique of existing works of research. According to Schaffner (1994), academic journals play pivotal roles within scholarly communities through five different roles. First, an academic journal must communicate information among scholars working in a particular field. Secondly, through such communication, a journal may not only construct and develop scientific communities, but it can also link a scholarly community together in a number of ways. Thirdly, by connecting a community of scholars, academic journals help to build a collective knowledge base. The fourth role is to make certain that relevant journals are comprised of the most comprehensive, upto-date, and authoritative archive of information in a given scholarly discipline. Lastly, the most significant role that academic journals may play is to form an archive of knowledge within a field (Schaffner, 1994).

Early and present-day scholars in the academic discipline of sport management have advocated for an ongoing process to develop a comprehensive body of knowledge with relevant and topical issues in the area of sport (Cuneen \& Parks, 1997; Fielding, Pitts, \& Miller, 1991; Mahony \& Pitts, 1998; Parks \& Quarterman, 2003). An important way to continue the growth of the field is through the analysis of publications of pertinent studies in the field. Specifically, Pedersen and Pitts (2001) stated that journal articles in the sport management academy should provide up-to-date theoretical constructs, as well as practical applications in order to ensure its relevance to professional and academic communities.

As the flagship journal of the Sport and Recreation Law Association, the Journal of Legal Aspects of Sport (JLAS) serves “... as an interdisciplinary outlet for legal issues in the sport, recreation, and related fields to meet the needs of researchers, academicians, practitioners, and policymakers" (About $J L A S$, para. 2). As Anderson (2001) stated:

... the Journal of Legal Aspects of Sport has a special place in the scholarly world. It presents legal issues affecting sport, physical education, and recreation for those who are not merely in law schools or the

\footnotetext{
* John J. Miller, $\mathrm{PhD}$, is a professor of sport management in the School of Marketing at the University of Southern Mississippi; email: john.j.miller@usm.edu. Andy Gillentine, PhD, is a professor of sport and entertainment management at the University of South Carolina. Andrew Olinger, MS, is a budget analyst for the Department of Athletics at The Ohio State University. Sara Vogt, $\mathrm{PhD}$, is an adjunct instructor in the College of Health and Human Services at Troy University.
} 
"traditional" legal world. Instead it draws on the expertise and experience of the many members of SSLASPA and others who study the legal aspects of sport from a different and decidedly scholarly perspective. (p. 97)

A study by Batista and Pittman (2006) identified $J L A S$ as the most highly ranked sport law journal among journals focusing on sport management. A sampling of quality journals that have cited $J L A S$ articles include University of Michigan Law Review, Harvard Journal of Sports and Entertainment Law, Harvard Journal of Law and Technology, Boston College Law Review, Cardozo Law Review, Stanford Law \& Policy Review, Ohio State Law Journal, Connecticut Law Review, and Hastings Law Journal (Spengler \& Miller, 2014). Furthermore, $J L A S$ articles have also been cited in well-respected journals such as Substance Use \& Misuse, Quest, Measurement in Physical Education and Exercise Science, Recreation Sports Journal, Journal of Sport Management, and the American Journal of Preventive Medicine.

Articles appearing in the Journal of Legal Aspects of Sport have informed court decisions and case outcomes, policy decisions and debate on limited liability legislation, health and safety issues, and universal access to sport opportunities (Spengler \& Miller, 2014). Additionally, JLAS articles have been cited in journals published in a variety of countries including India, China, Australia, France, Canada, the United Kingdom, and Spain (Spengler \& Miller, 2014). These inclusions indicate that the Journal of Legal Aspects of Sport has had some degree of success in attaining international recognition and appeal.

Although $J L A S$ addresses only legal-oriented articles, it adheres to a rigorous peer review process. Peer review is a broad term with a variety of meanings. Brown, Race, and Bull (1999) reported that peer review refers to a process that assists in the self-regulation of a profession. Additionally, peer review may apply to a process that necessitates experts in a (generally narrow) field to assess an author's work and ideas in that same field, usually for the purpose of publishing a paper or awarding a grant (Brown et al., 1999). Journals that make use of the peer review process, such as $J L A S$, generally use one of three systems: open, single-blind, or double-blind. Open peer review, as the name indicates, does not try to disguise the identity of authors or reviewers. In the single-blind review process, the identity of the reviewer is hidden from the author but not the other way around. Journals that employ double-blind reviews, such as $J L A S$, do not allow the identity of the reviewer or the author to be revealed to each other. With the help of such expert insights, editors are better able to verify the significance of the submitted manuscripts, which allows them to publish a body of dependable information for future researchers in the area to consider (Cohen, Keiper, Rosen, Crawford, \& Rubin, 2006).

Although JLAS has been published since 1992, a complete formal analysis of the content has never been conducted. A content analysis of JLAS may provide critical information regarding the diversity of topics covered, the specific research types utilized, demographic information regarding the authors published, and perhaps identify any gaps that may exist in the current literature base. Therefore, the purpose of this study was to conduct a content analysis of articles published in the Journal of Legal Aspects of Sport (JLAS) from 1992-2016. 


\section{Content Analysis}

Content analysis is a process of analyzing written, verbal, or visual communication messages (Cole, 1988). Content analysis has been defined as a systematic, replicable technique for condensing numerous words of text into a smaller number of content categories predicated on the rules of coding (Krippendorff, 1980; Weber, 1990). It has been used to analyze diverse areas such as organizational behavior (Duriau, Reger, \& Pfarrer, 2007), medical and bioethics literature (Forman \& Damschroder, 2008), and gender analysis (Neuendorf, Gore, Dalessandro, Janstova, \& SnyderSuhy, 2010). Additionally, content analysis has been used in sport related literature including studies on the use of sports celebrities in advertising (Stone, Joseph, \& Jones, 2003), online marketing (Brown, 2003), description requirements in the sport business industry (Bae \& Miller, 2012), and other academic sport management journals (Mondello \& Pesdersen, 2003; Pedersen \& Pitts, 2001; Peetz \& Reams, 2011; Pitts \& Pedersen, 2005). The goal of content analysis is to "provide knowledge and understanding of the phenomenon under study" (DowneWamboldt, 1992, p. 314).

Using content analysis appropriately emphasizes underlying implications of the words or the content (Babbie, 1992; Catanzaro, 1988; Morse \& Field, 1995). Content analysis should not merely be relegated to simply counting words to analyze language for the purpose of classifying large amounts of text into an efficient number of categories that represent similar meanings (Weber, 1990). It can be a useful method to uncover and depict the focus of individual, group, institutional, or social attention (Weber, 1990). It also permits the use of inferences to be made, which can then be substantiated by using other methods of data collection.

\section{Purpose}

Although content analysis has been conducted on several sport management journals, (i.e., European Journal of Sport Management, Journal of Sport Management, Journal of Sports Economics, International Journal of Sport Management, and Sport Marketing Quarterly) to date there has been no complete and formal analysis of the Journal of Legal Aspects of Sport. A content analysis of JLAS may provide critical information regarding the diversity of topics covered, the specific research types utilized, demographic information regarding the authors published, and perhaps identify any gaps that may exist in the current literature base.

\section{Methodology}

\section{Measures}

Riffe, Lacy, and Fico (1998) indicated that when researchers have identified a construct they wish to study, content analysis can be reduced to three essential steps: selecting representative samples of content, training coders to use category rules developed to determine differences in content, and assessing the reliability (agreement or stability over time) of coders in applying the rules. The collected 
data are analyzed to depict typical patterns or characteristics or to recognize significant relationships among the content qualities examined.

\section{Procedures}

Following three essential steps recommended by Riffe et al., (1998), the researchers of this study identified all articles published in JLAS from 1992 to 2016. Two sport management graduate students, with training, experience, and education in coding, analyzed all of the articles published in JLAS between 1992 and 2016. Each coder was able to access all of the articles through archives present on the $J L A S$ website. It is important to note that each coder was a member of the Sport and Recreation Law Association, which allowed them to access the archives at the time of the study. In 2018, JLAS transitioned to an open-access journal, thus its archives are freely available to anyone.

The second step involved creating a protocol for identifying and categorizing the target variable(s), and training coders to use this protocol. The content area categorization reflected the most cited studies published in JLAS as first identified by Spengler and Miller (2014) and later expanded by Miller, Gillentine, and Herbst (2015). Twenty categories were used to code the legal content areas of each article. The categories were 1) anti-trust/labor law; 2) drug testing/ doping; 3) Olympic issues; 4) Constitutional law; 5) intellectual property; 6) products liability; 7) contracts/waivers; 8) international issues; 9) professional sports/leagues; 10) criminal law; 11) media/social media; 12) risk management; 13) disabilities/ADA; 14) NCAA issues; 15) tax; 16) discrimination issues; 17) negligence/torts; 18) violence and hazing; 19) pedagogical issues; and 20) youth and interscholastic sport.

Given the a priori purpose of using the identified categories as a framework, the authors did not adopt a pure grounded theory approach (Glaser \& Strauss, 1967). Rather, a hybrid approach (Podlog \& Dionigi, 2010) was employed in order to enable the emergence of key themes from the data. The analysis involved intratextual (i.e., within-text) and intertextual (i.e., cross case) analysis of the data using the constant comparative method of analysis (Maykut \& Morehouse, 1994).

Investigator triangulation was addressed by the independent analyses of the data using the constant comparative method by trained content coders. The trained coders had completed graduate level classes in qualitative research methods and data analysis. The training process further involved several meetings between the authors and the content coders in which the described categories were analyzed to ensure familiarity with the constant comparative method of analysis. During these meetings, the qualitative technique of researcher reflexivity was used to ensure that personal values, assumptions, and potential biases did not consciously influence the analysis or interpretation of results. For example, discussions among research team members revealed the importance of minimizing the influence of personal perceptions when analyzing and interpreting the results.

The third step occurred after the transcript had been coded and the data were analyzed either to describe the target variable(s) or to identify emergent themes. Following a procedure developed by Hara, Bonk, and Angeli (2000), experienced individuals were used to validate code sheets. To preclude misconceptions or misinterpretations and to ensure reliability, the graduate students worked 
autonomously to code the identified categories. Rourke, Anderson, Garrison, and Archer (2001) stated that:

the reliability of a coding scheme can be viewed as a continuum, beginning with coder stability (intra-rater reliability; one coder agreeing with herself over time), to inter-rater reliability (two or more coders agreeing with each other), and ultimately to replicability (the ability of multiple and distinct groups of researchers to apply a coding scheme reliably). (p. 7)

Inter-rater reliability is a critical concern in relation to content analysis. It is regarded as the primary test of objectivity in content studies and defined as "the extent to which different coders, each coding the same content, come to the same coding decisions" (Rourke et al., 2001, p. 6). Content analysis research, "with reliability assessment below .70 becomes hard to interpret and the method of dubious value to replicate" (Riffe et al., 1998, p. 131). Upon completion of the first 10 descriptions, intercoder reliability was tested to ensure the consistency of the individuals (Potter \& Levine-Donnerstein, 1999). Agreement between the coders was $83 \%$ and the correction for chance agreement (Scott's [1955] Pi) was over .900 for each variable coded.

Once the coding was completed, a devil's advocate method was employed by two senior faculty members to challenge potential biases and assumptions of the graduate students involved in the data analysis process (Bowers, Martin, Miller, Wolfe, \& Speed, 2013; Cresswell, 2005; Lunenburg, 2012). The role of the devil's advocate is to challenge the assumptions and alternatives presented (Shimizu \& Hitt, 2004). The devil's advocate approach is used to prevent groupthink as well as to stimulate in-depth discussions and thought processes (MacDougall \& Baum, 1997). As a result, the devil's advocate approach may prevent biases from occurring (Shimizu \& Hitt, 2004). Discussions and review of selected categories allowed the researchers to critically reflect on the identification of the emergent themes.

\section{Results}

The data gathered in this study were used to investigate specific aspects of the state of the research literature published in the Journal of Legal Aspects of Sport from 1992 to 2016. The following are the findings of this analyses.

\section{Number and Length of Articles}

The articles were analyzed to disclose the state of the literature in JLAS from 1992 to 2016. Fifty-five issues of $J L A S$ were included for analysis beginning with the 1992 Spring issue of Volume 2 to the 2016 August issue of Volume 26. Overall, the results indicated that 257 peer-reviewed articles were published in $J L A S$ during the timeframe examined in this study.

The journal was published two times per year through its first four years in existence. For volumes six through $12, J L A S$ was published three times a year (between 1996 and 2002). Beginning with Volume 13 in 2003 until the present, $J L A S$ has been condensed back to two publications per year. The average number 
of articles in each issue was 5.60. This number is inflated from the Spring 1992 through Fall 1995 timeframe, when the average number of articles was 8.80. The number of articles in each issue ranged from a low of two (achieved two times, Spring 1999 and Winter 2014) and a high of 14, which was achieved one time in the Spring 1992 issue. The average number of pages for each issue was 86.33 pages. The number of pages ranged from a low of 70 in Volume 9, Number 2 in 1999, to a high of 168 pages in Volume 18, Number 1 in 2008.

Over the past 24 years, the journal has averaged just over three issues and 13 peer-reviewed empirical research articles each year. There was an average of just under five (4.5) research articles published each issue. The number of articles in each issue ranged from two to seven. Fourteen issues $(25 \%)$ contained four articles and $13(23 \%)$ had five articles. Ten issues (19\%) had three articles while seven issues $(14 \%)$ had seven articles, and six issues $(12 \%)$ had six articles. Three issues had two articles each and one issue had no research articles. Regarding the number of pages per study, 46 (37\%) were between $21-30$ pages, $44(36 \%)$ were between 31-40 pages, and 21 (17\%) were between 11-20 pages. All other publications lengths accounted for less than $10 \%$ of the total.

\section{Citation Guideline Format}

The two types of citation formats used in the articles were the guidelines of the Publication Manual of the American Psychological Association (APA) or Citator/Bluebook (BlueBook). Of the articles published in JLAS between 1992 and 2016, six (2\%) used a combination of BlueBook and APA publication style, 198 (77\%) used only APA, and 53 (21\%) strictly used BlueBook.

\section{Research Methodology}

Following the procedures established by Olafson (1990) and Barber, Parkhouse, and Tendrick (2001), the research articles were first analyzed and coded according to research methodology. For each of the articles, the coders were asked to identify the most appropriate type of research methodologies, such as qualitative, quantitative, or case studies (Noor, 2008), that had been used in the study, excluding commentaries, book reviews, or other miscellaneous articles. Qualitative research is contextual and subjective versus quantitative research, which tends to be generalizable and objective (Whittemore, Chase, \& Mandle, 2001). Additionally, qualitative research does not employ statistical analysis of any type to describe findings of the investigation, while quantitative research uses statistics to analyze the results (Arndt \& Bigelow, 2000; Bartunek, Bobko, \& Venkatraman, 1993). Case studies emphasize a particular issue or feature of analysis that allows the researcher to study the issue more intently (Noor, 2008, Patton, 1987). Using the aforementioned descriptions, the results indicated that $187(73 \%)$ articles were classified as qualitative studies, $64(25 \%)$ articles were classified as quantitative research, and six (2\%) case studies were published from 1992 to the Fall 2016 issue. 


\section{Article Content}

A content analysis of the 257 articles identified each of the topical areas reflecting the main focus. The area of risk management was the focus of the largest number of articles, identifying 61 (24\%) articles of which this was the primary or secondary focus. The second greatest number of article content dealt with legal issues associated with the NCAA $(53,21 \%)$. The area of negligence was the content area that had the third most published articles with a total of $36(14 \%)$. Gender discrimination issues was the fourth most published area of content, with $33(13 \%)$ articles. Additional areas were the legal application of contracts and waivers to sport and recreation $(28,11 \%)$ and Constitutional law (27, 11\%); intellectual property $(25,10 \%)$; professional sports $(23,9 \%)$; criminal law as well legal aspects pedagogy (15, 6\% each), and disability issues $(13,5 \%)$.

\section{University Carnegie Classifications}

The coders were asked to next identify the Carnegie Classification of the author's institution. The Carnegie Classification is the leading framework for classifying colleges and universities in the United States and was first implemented in 1970 (McCormick \& Zhao, 2005). The Carnegie Classification is often used to represent differences in institutional mission. Operationally, the Carnegie Classification identifies an institution as Doctoral/Research-Extensive, Doctoral/ResearchIntensive, Master's Colleges and Universities, Baccalaureate Colleges-Liberal Arts, and Baccalaureate Colleges_-General (McCormick, Pike, Kuh, \& Chen, 2009). These classifications differentiate institutions according to instructional program (separately for undergraduate and graduate education), research expectancies, enrollment profile (overall and undergraduate), and size and residential character (Carnegie Foundation for the Advancement of Teaching, 2008).

The results indicated that $122(47 \%)$ of the authors were employed at a Very High Research institution, followed by 48 (19\%) of those employed at High Research institutions. There were $46(18 \%)$ who performed research at Doctoral Research universities. Masters level and bachelor level colleges and universities accounted for $39(16 \%)$ of the authors. Fourteen (5\%) of the authors were involved in the professional law or sport industry. Finally, because six $(2 \%)$ of the authors were from international universities, they could not be categorized as a Carnegie Classification as no such designation exists outside of the United Sates.

\section{Authorship of Articles}

\section{Number of Authors per Article}

From 1992 until Fall 2016, a total of 398 authors were associated with the 257 journal articles published during this time, which represents slightly less than two (1.53) authors per article. Solo authored works (109) made up the highest percentage $(42 \%)$ of articles. The second highest category, two co-authors, was comprised of 106 research articles (41\%). Fifty-one articles (17\%) had three or more co-authors. 


\section{Author Gender}

Regarding the gender makeup of the 398 authors, 277 (70\%) were male and 122 $(30 \%)$ were female. Of the 257 single or lead-author articles, $165(64 \%)$ were by male authors and $92(36 \%)$ were by female authors. Of the 141 authors who were secondary authors (their names were listed second, third, fourth, or sixth on the authorship byline), 109 (77\%) were male authors and $32(23 \%)$ were female authors.

\section{Discussion}

There are several conclusions that can be drawn based upon the findings of this study. The first of note is that the Journal of Legal Aspects of Sport has contributed to the expansion of the sport management and sport law literature base. Since its inception in 1992 until the 2016 Fall issue, JLAS has published 257 research articles, which have expanded the knowledge base for the study of legal aspects in sport. As interest and study into the legal aspects of sport continue to grow, the potential impact of $J L A S$ will continue to increase.

In regards to quantity of publication, articles, and article length, the findings of this study were similar to other studies of sport management-related journals (Pedersen \& Pitts, 2001; Pitts, Danylchuk, \& Quarterman, 2014; Pitts \& Pedersen, 2005). This indicates a consistent level of professional expectation in terms of research format and submission requirement. A major difference in the analysis of $J L A S$ in comparison to other sport management-related journals was the acceptance and inclusion of different writing styles. The results indicated that $77 \%$ of the publications used APA and $20 \%$ used BlueBook citation styles. This flexibility in formatting should continue to encourage not only a variety of writing styles but may also be instrumental in the continued inclusion of individuals who are trained and educated in law school. The different types of writing styles may also be a factor in the high number of solo authored articles that made up $43 \%$ of the articles included in the study.

The results indicated that the top four areas of content of published articles dealt with risk management, NCAA legal issues, negligence, and gender discrimination. Interestingly, the legal issue addressed in these publications mirrored the results of previous studies regarding the topics covered in legal aspects courses. Cotten (1991) as well as Batista and Pittman (2006) found that negligence was the primary content area that faculty spent the most time teaching in class. Batista and Pittman (2006) as well as Young (2001) also reported that a majority of faculty taught risk management in legal issues classes. Thus, it appears that the legal research studies significantly relate to the topics that are most often taught in the classroom. While NCAA legal issues and gender discrimination were identified as primary content areas of publication in JLAS, Cotten (1991), Batista and Pittman (2006), nor Young (2001) identified either as main teaching areas. However, this may change if a future analysis of legal topics being taught at the undergraduate and graduate levels is conducted.

The findings of this study are consistent with analyses of the Sport Marketing Quarterly (Pederson \& Pitts, 2001) and the Journal of Sport Management (Pitts \& Pederson, 2005), in which female authors were in the minority. Sixty-five percent of the first authors in this study of $J L A S$ were male compared to $35 \%$ 
female. This disparity is even greater when all levels of authorship (solo, lead, or secondary) are considered, as 70\% were male and 30\% female. This result is reflective of other content analysis studies of sport management academic journals. In a content analysis of the Journal of Sport Management, Pitts and Pedersen (2005) reported that the percent of peer-reviewed research articles authored by male and female authors was $61 \%$ and $36 \%$, respectively. Pitts, Danylchuk, and Quarterman (2014) indicated that $78 \%$ of the authors were male while $22 \%$ were female. While this may be reflective and/or consistent with other research, it is an area in need of further analysis.

There is also conjecture that authors affiliated with a higher Carnegie Classification ranking institution have better opportunities to have a manuscript published (Yamamoto, 2004). An analysis of the authors provides interesting information regarding the type of institution in which they are employed. The authors contributing to $J L A S$ were identified by the current Carnegie Classification of their institution. Utilizing this classification system allows researchers to compare and contrast findings among similar and dissimilar characteristics.

Of the authors contributing to $J L A S$ during the timeframe of the study, more than $60 \%$ were employed by Very High Research or High Level Research institutions. An additional 16\% of the authors worked at Doctoral Research institutions. Traditional scholarly productivity in various forms has become a comprehensive expectation for promotion and tenure at all types of four-year colleges and universities (Bok, 1992; Fairweather, 2005). In particular, research intensive universities generally predicate faculty tenure and promotion (and the potential salary increases) with regard to research productivity (Fairweather, 2005). Breneman and Youn (1988) stated, "large research universities and graduate-training institutions are in the market for different kinds of services than are institutions that emphasize undergraduate teaching; ... organizations with an emphasis on research offer a distinctively different form of rewards" (p. 3). While a significant number of authors from these types of institutions would be expected to some degree due to tenure and promotion requirements typically associated with them, it is notable that more than $75 \%$ of the authors were published in the Journal of Legal Aspects of Sport. This result may lend credence to a previous study that identified $J L A S$ as the most highly ranked sport law journal within the field of sport management (Batista \& Pittman, 2006). Thus, authors from more research intensive universities may be more inclined to submit studies to JLAS due to its reputation in the field.

Another surprising result was the $7 \%$ of authors who were not associated with institutions with the Carnegie Classification system as well as the 5\% of authors who had no affiliation with an institution of higher education. The relatively small number of industry professional authors seems to be contrary to the mission of $J L A S$, which states that it "serves as an interdisciplinary outlet for legal issues in the sport, recreation, and related fields to meet the needs of researchers, academicians, practitioners, and policymakers" (About $J L A S$, para. 2).

This finding substantiates the need to evaluate the level of engagement, both through SRLA membership as well as JLAS readership by industry professionals. Anecdotal evidence indicates that industry professionals are involved with the organization at the annual conference but that does not appear to translate to 
publications on behalf of this population. The current list of $J L A S$ Review Board members identifies two thirds of its members as having a juris doctorate (JD) who are faculty members at universities. However, the listing identifies only one person as a full-time working industry professional. Additionally, only one Review Board member was associated with an international university. It would be interesting to include more sports industry legal professionals and international scholars on the $J L A S$ Review Board to monitor a potentially positive impact of submissions from those populations.

\section{Conclusion}

Content analysis is an important research tool for more rigorous study of the empirical results of conventional analyses. Significantly, content analysis can recognize certain patterns (which are sometimes hidden from the naked eye of casual readers), to be explored more in-depth. When conducted appropriately, content analysis provides an opportunity to systematically and objectively document what is published in a journal over a period of years.

The Journal of Legal Aspects of Sport is unique in the field of sport management as it is the only recognized journal that deals exclusively with legal issues in sport, recreation, and physical activity. It is heartening to contemplate about the potential breadth and scope of the work of $J L A S$ journal authors, and the potential to expand the reach of the journal into additional fields and disciplines. For example, Spengler and Miller (2014) reported that JLAS has been cited by journals in a variety of fields, including business, law, education/pedagogy, public policy, administration, marketing, health and medicine, and federal law enforcement training as well as in international forums. Thus, JLAS truly has an important place for academicians and practitioners in sport management and related fields.

In order to effectively and efficiently monitor the continued scholarly efforts of $J L A S$, it will be necessary to replicate this study in the future and compare the results to the current findings. Replicating this study will allow scholars to further analyze the professional and academic growth of the field and journal. It is imperative that the academic discipline continues to ascertain if it is meeting the needs of the academy and of the legal profession in terms of not only legal research production but also with regard to focus. Continued systematic analysis of the Journal of Legal Aspects of Sport will help future scholars identify areas of legal publication that may be oversaturated and perhaps more importantly those areas that are underrepresented or ignored. It is only through this conscientious type of introspection that an academic discipline can continue to evolve.

\section{References}

About JLAS. (2016). Mission. Retrieved from http://journals.humankinetics.com/page/about/JLAS

Anderson, P. (2001). SSLASPA: The new beginning. Journal of Legal Aspects of Sport, 11, 97-98. https://doi.org/10.1123/JLAS.11.1.97

Arndt, M., \& Bigelow B. (2000). Presenting structural innovation in an institutional environment: Hospitals' use of impression management. Administrative Science Quarterly, 45, 494-522. https://doi.org/10.2307/2667107 
Babbie, E. (1992). The practice of social research. New York, NY: Macmillan.

Bae, S., \& Miller, J. (2011). A content analysis of sales and marketing job description requirements in the sport business industry: What should students be prepared for? International Journal of Sport Management, 12, 379-392.

Barber, E., Parkhouse, B., \& Tendrick, T. (2001). A critical view of the methodology of published research in the Journal of Sport Management from 1991 through 1995 as measured by selected criteria. International Journal of Sport Management, 2, 216-236.

Bartunek, J., Bobko, P., \& Venkatraman, N. (1993). Toward innovation and diversity in management research methods. Academy of Management Journal, 36, 1362-1373.

Batista, P. J., \& Pittman, A. (2006). Descriptive analysis of SRLA members and the study of sport law in academia. Journal of Legal Aspects Sport, 16, 217-238. https://doi.org/10.1123/ JLAS.16.2.217

Bok, D. (1992). Reclaiming the public trust. Change: The Magazine of Higher Learning, 24(4), 12-19. https://doi.org/10.1080/00091383.1992.9937114

Bowers, A., Martin, C., Miller, J., Wolfe, B., \& Speed, N. (2013). “I feel pressure”: Exploring the phenomenon of body image formation in collegiate female athletes within the context of Social Comparison Theory. Journal of Coaching Education, 6(2), 2-26. https://doi.org/10.1123/ jce.6.2.2

Breneman, D. W., \& Youn, T. I. K. (1988). Academic labor markets and careers. New York, NY: Falmer Press.

Brown, M. T. (2003). An analysis on online marketing in the sport industry: User activity, communication objectives, and perceived benefits. Sport Marketing Quarterly, 12, 48-55.

Brown, S., Race, P., \& Bull, J. (1999). Computer-assisted assessment in higher education. Herndon, VA: Stylus Publishers, Inc.

Carnegie Foundation for the Advancement of Teaching. (2008). Basic classification. Retrieved from http://www.carnegiefoundation.org/classifications/index.asp?key=791

Catanzaro, M. (1988). Using qualitative analytical techniques. In P. Woods \& M. Catanzaro (Eds.), Nursing research: Theory and practice (pp. 437-456). New York, NY: C.V. Mosby Company.

Cohen, E., Keiper, A., Rosen, C., Crawford, M. B., \& Rubin, C. T. (2006). Rethinking peer review. The New Atlantis, 13, 106-110.

Cole, F. L. (1988). Content analysis: Process and application. Clinical Nurse Specialist, 2, 53-57. https://doi.org/10.1097/00002800-198800210-00025

Cotten, D. J. (1991). Current status of sport law courses. Journal of Legal Aspects of Sport, 1, $50-56$.

Cresswell, J. (2005). Educational research: Planning, conducting, and evaluating quantitative and qualitative research (2nd Ed.). Upper Saddle River, NJ: Pearson Education.

Cuneen, J., \& Parks, J. (1997). Should we serve sport management practice or sport management education? A response to Weese's perspective. Journal of Sport Management, 11, 125-132. https://doi.org/10.1123/jsm.11.2.125

Downe-Wamboldt, B. (1992). Content analysis: Method, applications, and issues. Health Care for Women International, 13, 314. https://doi.org/10.1080/07399339209516006

Duriau, V. J., Reger, R. K., \& Pfarrer, M. D. (2007). A content analysis of the content analysis literature in organization. Organizational Research Methods, 10, 5- 32. https://doi. org/10.1177/1094428106289252

Fairweather, J. S. (2005). Beyond the rhetoric: Trends in the relative value of teaching and research in faculty salaries. The Journal of Higher Education, 76, 401-422. https://doi.org/10.1353/ jhe.2005.0027 
Fielding, L., Pitts, B., \& Miller, L. (1991). Defining quality: Should educators in sport management programs be concerned about accreditation? Journal of Sport Management, 5, 1-7. https://doi. org/10.1123/jsm.5.1.1

Forman, J., \& Damschroder, L. (2008). Quantitative content analysis. In L. Jacoby \& L. Siminoff (Eds.), Empirical methods for bioethics: A primer (pp. 39-62). Oxford, UK: Elsevier Ltd.

Glaser, B., \& Strauss, A. (1967). The discovery of grounded theory: Strategies for qualitative research. Chicago, IL: Aldine.

Hara, N., Bonk, C. J., \& Angeli, C. (2000). Content analysis of online discussion in an applied educational psychology course. Instructional Science, 28, 115-152. https://doi. org/10.1023/A:1003764722829

Krippendorff, K. (1980) Content analysis: An introduction to its methodology. Newbury Park, CA: Sage Publications.

Lunenburg, F. (2012). Devil's advocacy and dialectical inquiry: Antidotes to groupthink. International Journal of Scholarly Academic Intellectual Diversity, 14(2), 1-9.

Mahony, D., \& Pitts, B. (1998). Research outlets in sport marketing: The need for increased specialization. Journal of Sport Management, 12, 259-272. https://doi.org/10.1123/jsm.12.4.259

Maykut, P., \& Morehouse, R. (1994). Beginning qualitative research: A philosophic and practical guide. London, UK: The Falmer Press.

McCormick, A. C., Pike, G. R., Kuh, G. D., \& Chen, P. S. D. (2009). Comparing the utility of the 2000 and 2005 Carnegie classification systems in research on students' college experiences and outcomes. Research in Higher Education, 50, 144-167. https://doi.org/10.1007/s11162-008-9112-9

McCormick, A. C., \& Zhao, C. M. (2005). Rethinking and reframing the Carnegie classification. Change: The Magazine of Higher Learning, 37(5), 51-57. https://doi.org/10.3200/CHNG.37.5.51-57

MacDougall, C., \& Baum, F. (1997). The devil's advocate: A strategy to avoid groupthink and stimulate discussion in focus groups. Qualitative Health Research, 7, 532-541. https://doi. org $/ 10.1177 / 104973239700700407$

Miller, J., Gillentine, A., \& Herbst, A. (2015). A content analysis of the Journal of Legal Aspects of Sport. Presented at the Sport \& Recreation Law Association national conference, Charlotte, NC.

Morse, J. M., \& Field P. A. (1995). Qualitative research methods for health professionals. Thousand Oaks, CA: Sage Publications.

Neuendorf, K., Gore, T., Dalessandro, A., Janstova, P., \& Snyder-Suhy, S. (2010). Shaken and stirred: A content analysis of women's portrayals in James Bond films. Sex Roles, 62, 747-761. https://doi.org/10.1007/s11199-009-9644-2

Noor, K. B. M. (2008). Case study: A strategic research methodology. American Journal of Applied Science, 5, 1602-1604. https://doi.org/10.3844/ajassp.2008.1602.1604

Olafson, G. A. (1990). Research design in sport management: What's missing, what's needed? Journal of Sport Management, 4, 103-120. https://doi.org/10.1123/jsm.4.2.103

Parks, J., \& Quarterman, J. (2003). Contemporary sport management. Champaign, IL: Human Kinetics.

Patton, M. Q. (1987). How to use qualitative methods in evaluation. Newbury Park, CA: Sage Publications.

Pedersen, P., \& Pitts, B. (2001). Investigating the body of knowledge in sport management: A content analysis of the Sport Marketing Quarterly. The Chronicle of Physical Education in Higher Education, 12(3), 8-9, 22-23. 
Pitts, B. G., \& Pedersen, P. (2005). Examining the body of knowledge in sport management: A content analysis of the Journal of Sport Management. Sport Management and Related Topics Journal, 2, 33-52.

Pitts, B., Danylchuk, K., \& Quarterman, J. (2014). A content analysis of the European Sport Management Quarterly and its predecessor the European Journal for Sport Management: 19842012. Choregia: Sport Management International Journal, 10(2), 45-72.

Podlog, L., \& Dionigi, R. (2010). Coach strategies for addressing psychosocial challenges during the return to sport from injury. Journal of Sport Sciences, 28, 1197-1208. https://doi.org/10.108 $\underline{0 / 02640414.2010 .487873}$

Potter, W., \& Levine-Donnerstein, D. (1999). Rethinking validity and reliability in content analysis. Journal of Applied Communication Research, 27, 258-284. https://doi. org/10.1080/00909889909365539

Riffe, D., Lacy, S., \& Fico, F. (1998). Analyzing media messages: Using quantitative content analysis in research. Mahwah, $\mathrm{NJ}$ : Lawrence Erlabaum.

Rourke, L., Anderson, T., Garrison, D. R., \& Archer, W. (2001). Assessing social presence in asynchronous text-based computer conferencing. Journal of Distance Education, 14(2), 50-71.

Scott, W. (1955). Reliability of content analysis: The case of nominal scale coding. Public Opinion Quarterly, 19, 321-325. https://doi.org/10.1086/266577

Schaffner, A. C. (1994). The future of scientific journals: Lessons from the past. Information Techonology and Libraries, 13, 239-247.

Shimizu, K., \& Hitt, M. A. (2004). Strategic flexibility: Organizational preparedness to reverse ineffective strategic decisions. The Academy of Management Executive, 18(4), 44-59.

Spengler, J. O., \& Miller, J. J. (2014). Perspectives on journal impact and the Journal of Legal Aspects of Sport. Journal of Legal Aspects of Sport, 24, 1-2. https://doi.org/10.1123/JLAS.2014$\underline{0005}$

Stone, G., Joseph, M., \& Jones, M. (2003). An exploratory study on the use of sports celebrities in advertising: A content analysis. Sport Marketing Quarterly, 10, 35-42.

Weber, R. P. (1990). Basic content analysis. Newbury Park, CA: Sage Publications. https://doi. org/10.4135/9781412983488

Whittemore, R., Chase, S. K., \& Mandle, C. L. (2001). Validity in qualitative research. Qualitative Health Research, 11, 522-537. https://doi.org/10.1177/104973201129119299

Yamamoto, K. (2004). What's in a name? The letterhead impact project. Journal of Legal Studies Education, 22, 65-98. https://doi.org/10.1111/j.1744-1722.2004.00011.x

Young, S. J. (2001). A content analysis of legal aspects courses in sport management. Journal of Legal Aspects of Sport, 11, 225-243. https://doi.org/10.1123/JLAS.11.3.225 